e-J. Surf. Sci. Nanotech. Vol. 4 (2006) 74-77

Conference - ISSS-4 -

\title{
Production of Propene Oxide by a Homogeneous Chain Reaction Initiated by Surface Radical Generation*
}

\author{
Naoki Mimura ${ }^{\dagger}$ \\ National Institute of Advanced Industrial Science and Technology (AIST), \\ 16-1, Onogawa, Tsukuba, Ibaraki, 305-8569 Japan, and \\ Division of Materials and Manufacturing Science, \\ Osaka University, 2-1, Yamada-oka, Suita, Osaka,565-0871, Japan \\ Zhaoxia Song and Susumu Tsubota \\ National Institute of Advanced Industrial Science and Technology (AIST), \\ 16-1, Onogawa, Tsukuba, Ibaraki, 305-8569 Japan \\ Hiromi Yamashita \\ Division of Materials and Manufacturing Science, \\ Osaka University, 2-1, Yamada-oka, Suita, Osaka,565-0871, Japan \\ S. Ted Oyama \\ National Institute of Advanced Industrial Science and Technology (AIST), \\ 16-1, Onogawa, Tsukuba, Ibaraki, 305-8569 Japan, and \\ Department of Chemical Engineering, Virginia Tech, Blacksburg, VA 24061, USA \\ (Received 14 October 2005; Accepted 20 December 2005; Published 19 January 2006)
}

\begin{abstract}
Effective Ti catalysts were found for the vapor phase synthesis of propylene oxide, one of the most challenging reactions in heterogeneous catalysis. The observation that the reaction was enhanced by the presence of a postcatalytic bed volume indicated that the reaction occurred through a homogeneous chain reaction, likely initiated by surface radical generation. EXAFS analysis of the $\mathrm{SiO}_{2}$-supported catalysts indicated that active samples had $\mathrm{Ti}$ oxide clusters on the support. The catalytic activity was stable for 500-600 min, and indicated a promising catalytic system. [DOI: 10.1380/ejssnt.2006.74]
\end{abstract}

Keywords: Extended X-ray absorption fine structure (EXAFS); Catalysis; Titanium oxide; Alkenes; Oxygen; Epoxidation; Radical generation

\section{INTRODUCTION}

Surface-initiated gas-phase reactions have been discussed only infrequently in the literature. One example is that of methane coupling with basic catalysts such as $\mathrm{Li}(\mathrm{MgO})$ or $\mathrm{Sm}_{2} \mathrm{O}_{3}$, which proceeds by the reaction of methane with surface centers to produce methyl radicals [1]. The methane activation step is slow and the high temperatures $(>873 \mathrm{~K})$ required for a significant reaction rate limit the selectivity, so the process has not been commercialized.

This paper presents results with a new system which allows the reaction of propylene and oxygen to proceed at relatively low temperatures $(\sim 573 \mathrm{~K})$, and gives rise to selective oxidation products without deactivation for the tested period (>500 min.). The system consists of Ti clusters supported on silica. Contrary to expectations, the main product is PO rather than the allylic oxidation product acrolein. Because the conditions are mild, good selectivities to partial oxidation products are obtained.

Propylene oxide (PO) is an important industrial product [2] currently manufactured by several indirect methods, such as the chlorohydrin process, which uses $\mathrm{Cl}_{2}$ and $\mathrm{H}_{2} \mathrm{O}$, or variations of the Halcon process, which use or-

* This paper was presented at International Symposium on Surface Science and Nanotechnology (ISSS-4), Saitama, Japan, 14-17 November, 2005.

†Corresponding author: n.mimura@aist.go.jp ganic hydroperoxides. Compared with the indirect methods, a process for direct epoxidation $\left(\mathrm{C}_{3} \mathrm{H}_{6}+1 / 2 \mathrm{O}_{2}=\mathrm{PO}\right)$ would be simpler and less expensive. However, the direct reaction is difficult because of the high reactivity of the hydrogens in the allylic position which on standard catalysts leads to products such as acrolein [3].

There has been considerable effort in the development of new catalysts and systems for the direct PO synthesis reaction. Examples are (1) silver-based catalysts [4], (2) gold nano-particle catalysts [5], (3) Ti-oxide catalysts [68], (4) molten salt catalysts [9], and (5) gas phase homogeneous reaction system [10]. These systems suffer from low selectivities and short lives. For example, gold nanoparticle catalysts have high selectivity ( $>98 \%$ ), but unfortunately short lives $(<6 \mathrm{~h})$. Similarly, Ti-oxide catalysts have high conversion $(>20 \%)$ but also have short lives $(<5 \mathrm{~h})$.

This paper reports results with a new system consisting of Ti-oxide clusters supported on silica which produces $\mathrm{PO}$ at relatively low temperatures $(\sim 573 \mathrm{~K})$ from only propene and oxygen. The clusters have a stable conversion over the course of the experiments.

\section{EXPERIMENTAL}

The Ti-oxide catalysts were prepared by impregnation of a silica support (Cariact Q-30, $120 \mathrm{~m}^{2} \mathrm{~g}^{-1}$, Fuji Silisia Chemical Ltd.) with Ti precursors. Two precursors were compared, a Ti dimer precursor complex [11] $\left(\left(\mathrm{NH}_{4}\right)_{8}\left[\mathrm{Ti}_{2}\left(\mathrm{C}_{6} \mathrm{H}_{4} \mathrm{O}_{7}\right)_{2}\left(\mathrm{O}_{2}\right)_{2}\right]_{2}-8 \mathrm{H}_{2} \mathrm{O}\right.$, Furuuchi Chemi- 
TABLE I: Initial activities of $\mathrm{TiO}_{2} / \mathrm{SiO}_{2}$ catalysts prepared from $\mathrm{Ti}_{2}$ complex. $\mathrm{T}=568 \mathrm{~K}, \mathrm{P}=3.5$ atm, Feed gas, $\mathrm{C}_{3} \mathrm{H}_{6}, 10$ $\mathrm{mL} \cdot \mathrm{min}^{-1}, \mathrm{O}_{2}, 10 \mathrm{~mL} \cdot \mathrm{min}^{-1}$. Catalyst weight, $1.0 \mathrm{~g}+$ quartz sand $3.0 \mathrm{~g}, 25-60 \mathrm{~min} .{ }^{a}$ post catalytic-bed volume, ${ }^{b}$ prepared from $\mathrm{Ti}_{2}$ complex, ${ }^{c}$ prepared from $\mathrm{Ti}(\text { iso- } \mathrm{PrO})_{4},{ }^{d}$ decomposed unsupported $\mathrm{Ti}_{2}$ complex, ${ }^{e}$ Post catalytic bed volume of the reactor filled with quartz sand. $\mathrm{T}=573 \mathrm{~K} . \mathrm{CO}_{x}=\mathrm{CO}, \mathrm{CO}_{2}$.

\begin{tabular}{|c|c|c|c|c|c|c|c|c|}
\hline \multirow[t]{2}{*}{ No. } & \multirow[t]{2}{*}{ Catalyst } & \multirow{2}{*}{$\begin{array}{l}\mathrm{PCBV}^{a} \\
(\mathrm{~mL})\end{array}$} & \multirow[t]{2}{*}{ Precursor } & \multirow{2}{*}{$\begin{array}{l}\text { Conversion of } \\
\mathrm{C}_{3} \mathrm{H}_{6}(\%)\end{array}$} & \multicolumn{4}{|c|}{ Selectivity (\%) } \\
\hline & & & & & $\mathrm{PO}$ & Acetaldehyde & $\mathrm{CO}_{x}$ & Other \\
\hline 1 & $\mathrm{TiO}_{2}{ }^{b}(2.0 \%) / \mathrm{SiO}_{2}$ & 25 & Dimer & 9.2 & 34.7 & 20.2 & 39.2 & 5.9 \\
\hline 2 & $\mathrm{TiO}_{2}{ }^{c}(2.0 \%) / \mathrm{SiO}_{2}$ & 25 & Monomer & 4.4 & 26.7 & 23.2 & 42.6 & 7.5 \\
\hline 3 & $\mathrm{TiO}_{2}^{b}(6.7 \%) / \mathrm{SiO}_{2}$ & 25 & Dimer & 11.1 & 28.1 & 19.0 & 45.0 & 7.9 \\
\hline 4 & $\mathrm{TiO}_{2}^{b}(15 \%) / \mathrm{SiO}_{2}$ & 25 & Dimer & 21.5 & 20.6 & 11.5 & 62.7 & 5.2 \\
\hline 5 & $\mathrm{TiO}_{2}^{d}$ & 25 & Dimer & 2.2 & 21.5 & 18.9 & 56.2 & 3.4 \\
\hline 6 & $\mathrm{SiO}_{2}$ & 25 & - & 0.2 & 35.5 & 41.7 & 20.0 & 2.8 \\
\hline $7^{e}$ & $\mathrm{TiO}_{2}(2.0 \%) / \mathrm{SiO}_{2}$ & None & Dimer & 1.9 & 1.6 & 18.4 & 49.6 & 30.4 \\
\hline
\end{tabular}

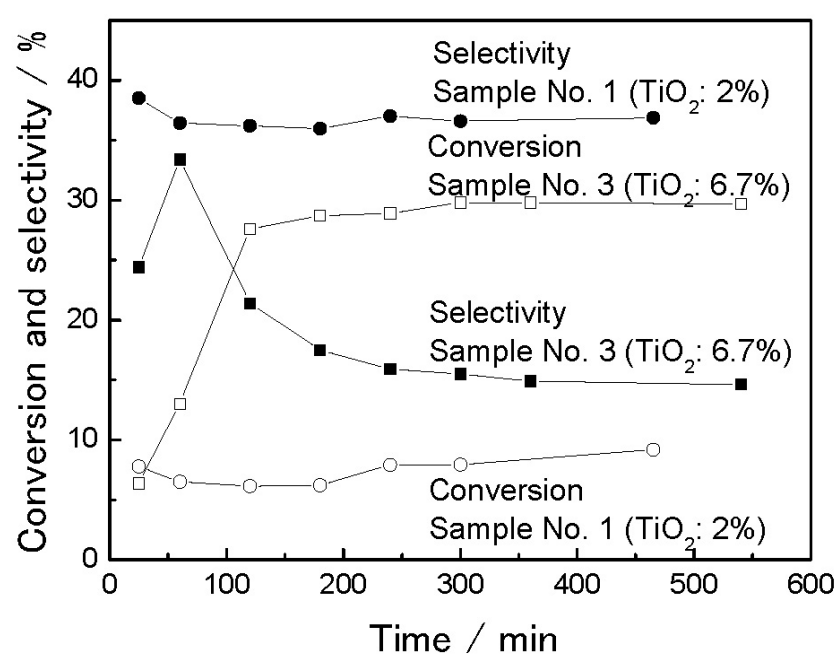

FIG. 1: Time course of PO formation using $\mathrm{TiO}_{2} / \mathrm{SiO}_{2}$ catalysts $\mathrm{T}=566 \mathrm{~K}, \mathrm{P}=: 3.5 \mathrm{~atm}$, Feed gas: $\mathrm{He} / \mathrm{C}_{3} \mathrm{H}_{6} / \mathrm{O}_{2}=5 / 5 / 10$ $\left(\mathrm{mL} \cdot \min ^{-1}\right)$.

cal), and a Ti monomer precursor [6] (Ti iso-propoxide) . Following impregnation the catalysts were vacuum dried at $343-353 \mathrm{~K}$ and calcined at $873 \mathrm{~K}$. The catalytic reactions were carried out in a stainless steel down-flow reactor with an inner quartz liner at $3.5 \mathrm{~atm}$ and 568-573 $\mathrm{K}$ with a feed consisting of $\mathrm{C}_{3} \mathrm{H}_{6} / \mathrm{O}_{2}=10 / 10\left(\mathrm{~mL} \cdot \mathrm{min}^{-1}\right)$ (Table 1) or $\mathrm{He} / \mathrm{C}_{3} \mathrm{H}_{6} / \mathrm{O}_{2}=5 / 5 / 10\left(\mathrm{~mL} \cdot \mathrm{min}^{-1}\right)$ (Fig. 1). The reactor had a volume section $(25 \mathrm{~mL})$ following the catalyst bed that could be empty or could be filled with quartz chips. The products were analyzed by two on-line gas chromatographs (Shimadzu, Model GC-14A, , Kyoto, Japan) equipped with FID and TCD detectors (4 ch). The columns employed were TC-FFAP, Porapack-Q, Gasukuropack-54, and Molecular sieve-5A. Product mass balances closed to $100 \% \pm 5 \%$. The X-ray absorption fine structure spectra (XANES and EXAFS) were obtained by the fluorescence method at the BL-7C beam line of the Photon Factory (High Energy Accelerator Research Organization, Ibaraki, Japan). The spectra were analyzed with REX 2000 (Rigaku, Tokyo, Japan) software. (Fitting range, $4-11 \AA^{-1}$, R-range, 0.98-3.38 $\AA$. The backscat- tering amplitude and phase shift functions were estimated by using the spectrum of anatase-type $\mathrm{TiO}_{2}$ as a standard material.) A sample of the dimer precursor was also calcined at $873 \mathrm{~K}$ to form a reference sample.

\section{RESULTS AND DISCUSSION}

Table 1 compares the activities of the $\mathrm{TiO}_{2} / \mathrm{SiO}_{2}$ catalysts, obtained mostly with an empty post-catalytic bed volume. Sample No.1, prepared from the Ti dimer complex precursor, shows good conversion and PO selectivity compared to Sample No.2, prepared from Ti isopropoxide (Ti monomer). The major side product in both cases was acetaldehyde. Samples with higher Ti loadings (Nos. 1, $3,4)$ gave higher propylene conversions, but slightly lower PO and acetaldehyde selectivities. Reference samples of the calcined titanium dimer precursor (unsupported) and the silica support duly gave low conversions (Nos. 5, 6). The high conversions of the supported sample suggest that the titanium oxide species are highly dispersed on the $\mathrm{SiO}_{2}$ support. A sample of the low loading (2\%) Ti dimer catalyst in which the post-catalytic-bed volume was filled with quartz sand (No. 7) gave low conversion. A blank experiment with no catalyst did not give any conversion. Comparison to Sample No. 2 indicates that the post-catalytic volume is essential for PO production using this type of catalyst. This is a strong indication that the reaction is occurring in the gas-phase through radical chain reactions. We speculate that the role of the $\mathrm{Ti}$ dimer catalyst is to generate radicals which initiate the reactions. We are currently designing an apparatus that will enable us to trap radical intermediates and to verify their existence with electron spin resonance spectroscopy.

The Ti oxide dimer catalysts showed good stability in the tested period (Fig. 1) in contrast with previously studied direct PO catalysts [5, 6]. An induction period was observed for the $\mathrm{Ti}(6.7 \%)$ catalyst. The cause may be related to the generation of radical species whose formation and disappearance need to be balanced gradually as they involve the establishment of radical branching steps. Induction periods have been reported in radical oxidation reactions [12]. The induction period does not appear with the $\mathrm{Ti}(2 \%)$ catalyst. The reason may be that be- 


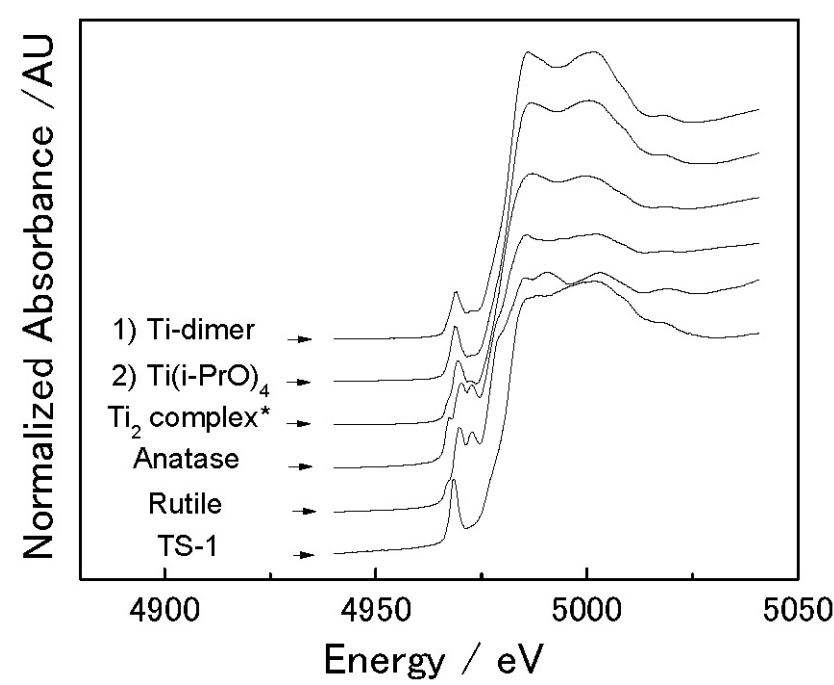

FIG. 2: Ti-K edge XANES a spectra of $\mathrm{TiO}_{2} / \mathrm{SiO}_{2}$ catalysts. Sample No. 1, prepared from titanium dimer complex. Sample No. 2, prepared from $\mathrm{Ti}(\text { iso- } \mathrm{PrO})_{4} .{ }^{*}$ Titanium source of catalyst No. 1, untreated.

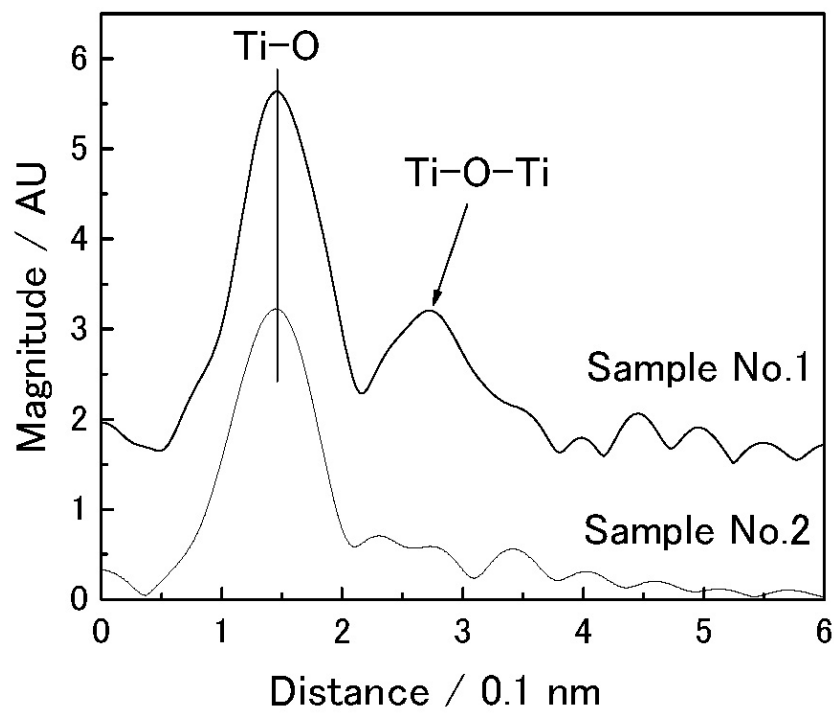

FIG. 3: FT-EXAFS spectra of $\mathrm{TiO}_{2} / \mathrm{SiO}_{2}$ catalysts.

cause of its lower activity the rate of formation of radicals was lower and reached a balance with the consumption of radicals in a short time.

Figures 2 and 3 show the XAFS spectra of the $\mathrm{TiO}_{2} / \mathrm{SiO}_{2}$ catalysts. From the XANES pre-edge peaks, it can be deduced that the structures of the Ti oxide species on the $\mathrm{SiO}_{2}$ support (Samples No. 1 and 2) are different from those of rutile and anatase type $\mathrm{TiO}_{2}$. In the EXAFS spectra of Samples 1 (dimer precursor) and 2 (monomer precursor), the first peak at $0.15 \mathrm{~nm}$ in both spectra are assigned to Ti-O bonds. In Sample 1, a second peak at $0.27 \mathrm{~nm}$ is clearly observed, and this is assigned to a Ti$\mathrm{Ti}$ distance in a Ti-O-Ti structure. The Ti-oxide species in Sample 1 might be deduced to have a cluster structure consisting of a few $\mathrm{Ti}$ atoms (2 or 3 ) bonded through bridging oxygen atoms. In contrast, the Ti monomer does not form a cluster structure with Ti-O-Ti bond, and the $\mathrm{Ti}$ species might be isolated on the $\mathrm{SiO}_{2}$ surface.

Formation of activated oxygen species on $\mathrm{Ti}$ centers from oxidants such as $\mathrm{H}_{2} \mathrm{O}_{2}$ in the liquid-phase epoxidation of alkenes using catalysts [13] like TS-1 is well-known. The radical generation function of the $\mathrm{Ti}$ cluster in this study is likely to be different. Although we do not have direct evidence, we hypothesize that the $\mathrm{Ti}$ oxide cluster with Ti-O-Ti structure could be effective in radical generation by stabilizing a $\mathrm{Ti}^{3+}$ state. Isolated tetrahedral $\mathrm{Ti}$ oxide species have been shown to produce $\mathrm{Ti}^{3+}$ in photocatalysts by UV radiation [14], or by reduction in $\mathrm{H}_{2}$ at $773 \mathrm{~K}$ [15]. After radical formation other oxygenates may be formed in the post-catalytic-volume by well-known gas-phase radical reactions [16-19]. The first species generated are likely to be allyl radicals which then interact with molecular $\mathrm{O}_{2}$ to form peroxy radicals that lead to the formation of peroxodimers or hydroperoxides. The hydroperoxides epoxidize propylene to PO and the peroxodimers decompose to form PO.

Surface-initiated gas-phase radical generation has been known for a long time. Lunsford [20] cites the work of Langmuir [21] in which hydrogen radicals were generated by incandescent tungsten wires (>1300 K). Other example include the formation of gas-phase methylallyl radicals during the oxidation of 1-butene and isobutylene over bismuth oxide at $723 \mathrm{~K}$ [22], the generation of radicals during the oxidative dehydrogenation of propane over a

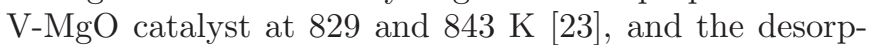
tion of hydroxyl radicals during the catalytic reactions of water or hydrogen with oxygen over basic metal oxides $(\mathrm{MgO}, \mathrm{CaO}, \mathrm{SrO}, \mathrm{BaO})$ in the temperature range $1100-$ $1300 \mathrm{~K}[24]$. In the case of propylene, Chelliah and Keulks report surface-initiated homogeneous reactions that produce propylene oxide over a bismuth molybdate catalyst operating at $698 \mathrm{~K}$ [25]. Our work can be distinguished from these previous studies by the remarkably low temperatures $(\sim 573 \mathrm{~K})$ at which the radicals are generated. This is probably a consequence of the unique properties of the Ti dimer complex which has a suitable structure for generating the radical.

\section{CONCLUSION}

In conclusion a catalyst containing Ti oxide dimers supported on $\mathrm{SiO}_{2}$ was prepared from a Ti dimer complex and was found to be effective for direct PO production. The catalyst was produced from a Ti dimer precursor by simple impregnation and thermal decomposition, and its structure was determined by EXAFS analysis. The production of PO likely occurred by a gas-phase radical chain reaction mechanism as deduced from the effect of the postcatalytic-bed volume.

\section{Acknowledgments}

We acknowledge financial support from the New Energy and Industrial Technology Development Organization of Japan (Industrial Research Grant Program, Project ID: 04A33006). We also thank National Laboratory for High 
[1] T. Ito, J. Wang, C. H. Lin and J. H. Lunsford, J. Am. Chem. Soc. 107, 5062 (1985).

[2] D. L. Trent, "Propylene Oxide", in Kirk Othmer Encyclopedia of Chemichal Technology, on-line edition, John Wiley \& Sons, New York, (2001).

[3] Chem. Eng. News July 5, 33 (1999).

[4] F. W. Zemichael, A. Palermo, M. S. Tikhov and R. M. Lambert, Catal. Lett, 80, 93 (2002).

[5] M. Haruta and M. Date, Appl. Catal. A 222, 427 (2001).

[6] K. Murata and Y. Kyozumi, Chem. Comnun. 2001, 1356 (2001).

[7] K. Murata, Y. Liu, N. Mimura and M. Inaba, Catal. Commun. 4, 385 (2003).

[8] K. Murata, Y. Liu, N. Mimura and M. Inaba, J. Catal. 220, 513 (2003).

[9] Olin Corp., U. S. Patent 4,992,567 (1991).

[10] T. Hayashi, L. B. Han, S. Tsubota, M. Haruta, Ind. Eng. Chem. Res. 34, 2298 (1995).

[11] M. Kakihana, M. Tada, M. Shiro, V. Petrykin, M. Osada and Y. Nakamura, Inorg. Chem. 40, 891 (2001).

[12] G. Franz and R. Sheldon, "Oxidation", in Ullmann's Encyclopedia of Industrial Chemistry, 5th Ed., B. Elrers, S. Hawkins and G. Schulz, Eds., VCH, Vol A18, p.261 (1991).
[13] M. G. Clerici, G. Bellussi and U. Romano, J. Catal. 129 , 159 (1991).

[14] H. Yamashita and M. Anpo, Current Opinion Solid St. Mat. Sci. 7, 471 (2004).

[15] C. Murata, H. Yoshida, J. Kumagai and T. Hattori, J. Phis. Chem. B 107, 4364 (2003).

[16] J. R. Lowe and N. A. Porter, J. Am. Chem. Soc. 119, 11534 (1997).

[17] J. W. Bozzelli and A. M. Dean, J. Phys. Chem. 97, 4427 (1993).

[18] M. E. Jenkin, T. P. Murrells, S. J. Shalliker and G. D. Hayman, J. C. S. Faraday Trans. 89, 433 (1993).

[19] N. D. Stothard and R. W. Walker, J. C. S. Faraday Trans. 88, 2621 (1992).

[20] J. H. Lunsford, Langmuir 5, 12 (1989).

[21] I. Langmuir, J. Am. Chem. Soc. 34, 1310 (1912).

[22] D. J. Driscoll, W. Martir and J. H. Lunsford, J. Phis. Chem. 91, 3585 (1987).

[23] K. T. Nguyen and H. H. Kung, J. Catal. 122, 415 (1990).

[24] S. Noda, M. Nishioka, A. Harano and M. Sadakata, J. Phis. Chem. B 102, 3185 (1998).

[25] D. Chelliah and G. W. Keulks, J. Catal. 24, 529 (1972). 